\title{
STUDI ASPEK HUNIAN BERKELANJUTAN PADA RUSUNAWA (OBJEK STUDI : RUSUNAWA RAWA BEBEK)
}

\author{
Abraham Marcelino ${ }^{1}$, Sylvie Wirawati ${ }^{2}$, I G Oka Sindhu Pribadi ${ }^{3}$ \\ 1) Program Studi S1 PWK, Fakultas Teknik, Universitas Tarumanagara, abraham.sihombing7@gmail.com \\ 2)Program Studi S1 PWK, Fakultas Teknik, Universitas Tarumanagara, sylview@ft.untar.ac.id \\ 3)Program Studi S1 PWK, Fakultas Teknik, Universitas Tarumanagara, okapribadi@cbn.net.id
}

\begin{abstract}
Abstrak
Rumah Susun Sewa merupakan program perumahan yang digunakan untuk mengatasi masalah perumahan khususnya di daerah perkotaan. Pemerintah DKI Jakarta dalam pembangunannya, memiliki salah satu visinya yaitu dapat terwujudnya permukiman yang berkelanjutan. Dipastikan bahwa tujuan dibangunya rusunawa ini tidak lepas dari aspek - aspek hunian berkelanjutan yang dimana memadukan aspek lingkungan hidup, sosial, dan ekonomi kedalam strategi pembangunan untuk menjami keutuhan lingkungan hidup serta keselamatan, kemampuan, kesejahteraan, dan mutu generasi saat ini dan generas masa depan. Oleh karena itu, penelitian ini bertujuan untuk melakukan studi terhadap Rusunawa Rawa Bebek salah satu rusunawa yang dibangun oleh DKI Jakarta dengan berlandaskan visi tersebut untuk melihat bentuk penerapan penerapan aspek berkelanjutan yang telah dilakukan dan melakukan evaluasi terhadapnya sehingga selain melakukan studi juga dapat memberikan saran dan rekomendasi terhadap aspek - aspek hunian keberlanjutan yang perlu ditingkatkan. Metode penelitian yang digunakan menggunakan metode kualitatif deskriptif. Hasil penelitian yang didapatkan adalah bahwa dalam penerapan aspek - aspek keberlanjutan khususnya di Rusunawa Rawa Bebek, aspek lingkungan merupakan aspek yang perlu banyak ditingkatkan. Karena pada aspek tersebut Rusunawa Rawa Bebek sudah memiliki sistemnya, tetapi belum berjalan optimal. Sedangkan untuk aspek sosial dan ekonomi Rusunawa Rawa Bebek sudah berjalan cukup baik dalam penerapanya. Dengan hasil ini, Rusunawa Rawa Bebek sudah menerapkan banyak aspek hunian berkelanjutan walaupun berbagai aspek tersebut perlu ditingkatkan agar tercapai suatu permukiman yang berkelanjutan yang lebih baik.
\end{abstract}

Kata kunci: Hunian berkelanjutan; Berkelanjutan; Rusunawa

\begin{abstract}
Rental Flats is a housing program that is used to solve housing problems. The Jakarta government, has one of its visions, namely the realization of sustainable settlements. It is certain that the purpose of building this flats cannot be separated from the aspects of sustainable housing which combines environmental, social and economic aspects into the development strategy to ensure the integrity of the environment as well as the safety, ability, welfare, and quality of current and future generations. Therefore, the purpose of choose the Rawa Bebek flats as study object is because this is one of the flats that built by Jakarta based on this vision and the purpose of this study is to see the forms of implementation of sustainable aspects that has been doing and evaluate them, so that apart from conducting studies, also can provide suggestions and recommendations on aspects of sustainable housing that need to be improved. The research method used is descriptive qualitative method. The results obtained are that in the application of sustainability aspects, especially in Rawa Bebek flats, environmental aspects are aspects that need to be improved a lot. Because in this aspect the Rawa Bebek flats already has the system, but it has not been running optimally. Meanwhile, the social and economic aspects of Rawa Bebek Rusunawa has been running quite well in their implementation. The Result, Rawa Bebek Flats has implemented many aspects of sustainable housing, although these aspects need to be improved in order to achieve a better sustainable settlement.
\end{abstract}

Keywords: Flats; Sustainable Housing; Sustainable 


\section{PENDAHULUAN}

\section{Latar Belakang}

Beragam permasalahan muncul dan berdampak terhadap memenuhi kebutuhan perumahan khususnya pada DKI Jakarta. Salah satu solusi yang diberikan adalah dengan membangun rumah susun. Pembangunan rumah susun ini memiliki visi salah satunya adalah terwujudunya permukiman yang berkelanjutan. Tujuan dari pembangunan permukiman yang berkelanjutan adalah agar memadukan aspek lingkungan, sosial, dan ekonomi kedalam suatu strategi untuk menjamin keselamatan, kemampuan, kesejahteraan, dan mutu dari generasi masa kini dan generasi masa depan (Undang - Undang Tentang Perlindungan dan Pengelolaan Lingkungan Hidup, 2009). Peneliti melakukan penelitian ini dikarenakan pentingnya berkelanjutan diterapkan pada sektor perumahan agar perumahan dapat mempunyai peran penting dalam krisis lingkungan secara global. Selain itu, urbanisasi global dan permukiman kumuh terjadi secara cepat di negara berkembang sehingga keterjangkauan perumahan berkelanjutan merupakan strategi yang penting dan genting. Terakhir, penerapan berkelanjutan masih sangat lemah di negara berkembang. Oleh karena itu, peneliti ingin melakukan penelitian terhadap salah satu rumah susun yang dibangun berdasarkan visi tersebut yaitu Rusunawa Rawa Bebek. Selain melakukan studi terhadap bentuk hunian berkelanjutan yang diterapkan di Rusunawa Rawa Bebek, peneliti juga melakukan evaluasi terhadap aspek tersebut. Diharapakan hasil penelitian ini, dapat berguna untuk meningkatkan penerapan hunian berkelanjutan di Rusunawa Rawa Bebek maupun terhadap rumah susun lainya.

\section{Rumusan Permasalahan}

Penelitian ini dilakukan dengan melihat terdapatnya beberapa permasalah terhadap aspek aspek hunian berkelanjutanya. Yaitu, terjadi tunggakan sewa penghuni Rusunawa Rawa Bebek karena kesulitan untuk mencapai tempat pekerjaannya (sebelum relokasi) dari segi jarak, waktu, dan biaya; banyak penghuni yang berjualan di luar dari tempat yang dikhususkan untuk berjualan sehingga menyebabkan makin berkurangnya ruang untuk bersama; budaya membuang sampah sembarangan di koridor maupun ruang bersama masih sering terjadi sehingga menyebabkan lingkungan hunian menjadi tidak bersih; dan pada aspek sosial, perbedaan asal relokasi tidak menjadi masalah pada orang tua tetapi terjadi pada anak - anak yang menyebabkan anak - anak hanya bermain dan berteman dengan asal relokasi mereka. Berbagai permasalahan ini yang menjadikan dasar untuk melakukan penelitian ini dikarenakan masalah ini terdapat pada aspek - aspek berkelanjutan sehingga peneliti ingin melihat lebih dalam bagaimana kondisi aspek - aspek berkelanjutan lainya di Rusunawa Rawa Bebek.

\section{Tujuan}

Tujuan penelitian dibagi menjadi tiga yang saling berurutan dan memiliki satu alur, yaitu untuk mengetahui bentuk penerapan aspek - aspek hunian berkelanjutan di Rusunawa Rawa Bebek, untuk mengetahui kondisi penerapan aspek - aspek hunian berkelanjutan di Rusunawa Rawa Bebek, dan untuk memberikan saran dan rekomendasi terkait aspek - aspek hunian berkelanjutan yang perlu ditingkatkan di Rusunawa Rawa Bebek. Sehingga penelitian ini diharapkan dapat memberikan manfaat terhadap pengelola Rusunawa Rawa Bebek dan Dinas Perumahan Rakyta dan Kawasan Permukiman DKI Jakarta selaku pelaksana program penyedia Rusunawa di DKI Jakarta agar memperhatikan aspek - aspek hunian berkelanjutan pada program rusunawa lainya.

\section{KAJIAN LITERATUR}

Landasan penelitian ini menggunakan indikator yang diambil dari buku Sustainable Housing For Sustainable Cities (Golubchikov \& Badyina, 2012) yaitu indikator hunian berkelanjutan dengan skala mikro dengan tiga aspek utamanya yaitu; Melakukan penghematan energi, air dan sumber daya, ramah lingkungan, menggunakan alternatif bahan konstruksi lokal dengan sifat yang 
berkelanjutan, sanitasi, untuk mencegah tercampurnya bahan berbahaya dan polutan bahaya, sumber daya yang digunakan terjangkau, meningkatkan ketahanan dan adaptasi dari rumah ; aspek sosial terdiri dari masyarakat diperdayakan dan menjamin keikutsertaan publik, kesehatan, keselamatan, kesejahteraan pada rumah tinggal, memastikan rasa kebersamaan, 'sense of place', dan identitas, memenuhi minimum keinginan di Kawasan hunian, menyediakan akses ke infrastruktur dan ruang publik; dan untuk aspek ekonomi yang terdiri dari memastikan ketrjangkauan permahan bgi kelompk-kelompok sosal yang berbeda, menyediakan tempat tinggal yang memadai untuk meningkatkan produktivits tenaga kerja, memastikan perumahan terintegrsi dngan pekerjaan, mendukung kegiatan ekonomi domestik dan perusahaan. Selain indikator dari UN-Habitat, terdapat beberapa indikator lainya yang diambil dari Green Impact Indonesia dalam jurnalnya (2010) yaitu untuk aspek ekonomi adalah dekat atau aksesibel menuju tempat kerja dan kegiatan sestiap hari; untuk aspek sosial yaitu berdekatan dengan tempat beribadah serta tempat interaksi sosial; dan untuk aspek lingkungan adalah aman dari bencana alam seperti banjir dan gempa serta dapat mengurangi dampak terhadap lingkungan sekitarnya (hemat energi dan pengelolaan sampah).

Selain kajian teori tersebut, peneliti juga mengambil beberapa referensi dari studi yang dilakukan oleh (Rosilawati, 2016) yang berjudul Konsep Hunian Berkelanjutan Pada Rumah Susun dan (Widyasari, 2017) yang berjudul Konsep Rumah Susun Berkelanjutan di Kawasan Industri. Penelitian tersebut digunakan sebagai bahan referensi hunian berkelanjutan dengan objek studi rusunawa dan bahan dasar melakukan penelitian ini.

\section{METODE PENELITIAN}

Jenis penelitian yang digunakan adalah deskriptif kualitatif. Jensi penelitian ini digunakan untuk mendeskripsikan kondisi setiap indikator aspek hunian berkelanjutan yang dilakukan di Rusunawa Rawa Bebek. Lalu hasilnya akan didalami dengan pendekatan kualitatif berupa metode riset secara deskriptif dengan mengacu pada data dan memanfaatkan teori hunian berkelanjutan sebagai bahan pendukung untuk memberikan saran dan rekomendasi.

Tehnik pengumpumpulan data yang digunakan berkaitan dengan pendekatan kualitatif yaitu untuk data primer beruba observasi yang dilakukan di Rusunawa Rawa Bebek untuk melihat kondisi penerapan aspek hunian berkelanjutan secara langsung dengan melakukan dokumentasi dan wawancara bebeas terpimpin yang bertujuan untuk mendapatkan data mengenai aspek hunian berkelanjutan yang diterapkan secara lebih luas dan lebih eksploratif dengan tetap terkendali.

Indikator aspek hunian berkelanjutan yang digunakan adalah sebagai berikut.

Tabel 1. Indikator Hunian Berkelanjutan

\begin{tabular}{|c|c|c|c|}
\hline No & Variabel & Sub Variabel / Indikator & Definisi Indikator \\
\hline \multirow{5}{*}{1} & \multirow{6}{*}{ Lingkungan } & \multirow{6}{*}{$\begin{array}{l}\text { Memastikan efisiensi } \\
\text { energi, generasi mikro, } \\
\text { air dan efisiensi sumber } \\
\text { daya }\end{array}$} & Meminalkan kebocoran dan air tumpah \\
\hline & & & Sistem pengumpulan air hujan \\
\hline & & & Penggunaan kembali air \\
\hline & & & $\begin{array}{l}\text { Menggunakan tehknologi yang mengurangi } \\
\text { laju air }\end{array}$ \\
\hline & & & $\begin{array}{l}\text { Memasang sistem meteran air (untuk } \\
\text { mengukur pengeluaran air) }\end{array}$ \\
\hline 2 & & & $\begin{array}{l}\text { Meningkatkan efisiensi utilitas mensuplai } \\
\text { rumah dengan listrik }\end{array}$ \\
\hline
\end{tabular}


Isolasi elemen struktural dengan lebih baik rumah - dinding, jendela, pintu, atap dikombinasikan dengan ventilasi yang lebih baik

Melengkapi rumah dengan energi terbarukan instalasi pembangkit listrik atau panas.

Memberi insentif dan mendisiplinkan rumah tangga melalui pengukuran energi dan penagihan

Masyarakat berperan aktif dalam pengelolaan sampah yang dikelola dengan bank sampah

Pengelolaan sampah didukung dengan penyediaan tempat sampah yang memadahi

Mempermudah sistem pengelolaan maka dilakukan pembedaan shaft sampah organik dan anorganik

4

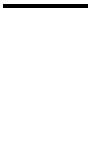

\begin{tabular}{c}
\hline 9 \\
\hline 10 \\
\hline 11 \\
\hline 12 \\
\hline 13 \\
\hline 14
\end{tabular}

Desain hijau, menggunakan konstruksi lokal yang berkelanjutan dan bahan

bahan - bahan berbahaya dan polusi lingkungan
Ramah lingkungan, dengan desain bangunan yang memanfaatkan pencahayaan dan penghawaaan alami

Memiliki pembuangan air kotor dan drainase yang terintegrasi dengan saluran pembuangan air kota

Pengelolahan dan Pemanfaatan Ulang Air dan daur ulang limbah: Pemenuhan sumber daya air dapat dilakukan dengan pengolahan air limbah rumah tangga yang dihasilkan rusun dengan IPAL

Pengadaan petugas keamanan dari

pemerintah,

Pembangunan infrastruktur lain seperti pos jaga, dinding keliling rumah susun,

Membangun kesadaran warga untuk saling mengawasi

Memberdayakan masyarakat (enpowerment) dengan Meningkatkan kegiatan pelatihan dan pembinaan dalam menciptakan keterampilan baru secara menyeluruh dan berkala

masyarakat dan memastikan partisipasi publik.

Memastikan partisipasi publik (partisipasi langsung dan tidak langsung) dengan partisipasi masyarakat secara langsung dalam keikutsertaan dalam membayar iuran dan memberikan ide ataupun pendapat

Keselamatan dari bencana kebakaran

Memastikan kesehatan, keselamatan, kesejahteraan pada rumah tinggal

Keselamatan dari bencana Gempa bumi Keselamatan dari bencana Banjir

Akses pelayanan kesehatan (pemerintah dan kesehatan)

dan keinginan d perumahan (termasuk yang terkait dengan
Akses pelayanan pendidikan

Akses pelayanan peribadatan 


\begin{tabular}{|c|c|c|}
\hline 15 & $\begin{array}{l}\text { jenis kelamin, usia dan } \\
\text { kesehatan) }\end{array}$ & Akses bagi penyandang cacat dan orang tua \\
\hline 16 & $\begin{array}{l}\text { Menyediakan akses ke } \\
\text { infrastruktur dan ruang } \\
\text { publik. }\end{array}$ & $\begin{array}{l}\text { Membangun akses jalan untuk memudahkan } \\
\text { pencapaian terhadap infrastruktur dan ruang } \\
\text { publik }\end{array}$ \\
\hline 17 & $\begin{array}{l}\text { Menciptakan rasa } \\
\text { kebersamaan, 'sense of } \\
\text { place', dan identitas. }\end{array}$ & $\begin{array}{l}\text { Memiliki fasilitas bersama yang mendukung } \\
\text { penghuni melakukan kegiatan sosial }\end{array}$ \\
\hline 18 & $\begin{array}{l}\text { Memastikan } \\
\text { keterjangkauan } \\
\text { perumahan bagi } \\
\text { kelompok-kelompok } \\
\text { sosial yang berbeda. }\end{array}$ & Uang Sewa yang terjangkau \\
\hline Ekonomi & $\begin{array}{l}\text { Menyediakan tempat } \\
\text { tinggal yang memadai } \\
\text { untuk meningkatkan } \\
\text { produktivitas tenaga } \\
\text { kerja; Memastikan } \\
\text { perumahan terintegrasi } \\
\text { dengan pekerjaan }\end{array}$ & $\begin{array}{l}\text { Memastikan perumahan terintegrasi dengan } \\
\text { pekerjaan }\end{array}$ \\
\hline 20 & $\begin{array}{l}\text { Mendukung kegiatan } \\
\text { ekonomi berbasis rumah } \\
\text { tangga (UBR)/Home } \\
\text { Based Enterprise. }\end{array}$ & $\begin{array}{l}\text { Mendukung kegiatan ekonomi berbasis rumah } \\
\text { tangga (UBR)/Home Based Enterprise }\end{array}$ \\
\hline
\end{tabular}

Sumber : Olahan Peneliti Berdasarkan Skala Hunian Berkelanjutan Skala Mikro UN - Habitat,2012 dan Green Impact Indonesia, 2010

\section{HASIL PENELITIAN}

Hasil dari penelitian ini dijabarkan dalam bentuk tabel dengan tujuan untuk mengetahui bentuk - bentuk penerapan dan kondisi penerapan setiap variabel hunian berkelanjutan di Rusunawa Rawa Bebek digabung menjadi satu tabel evaluasi. Berikut merupakan hasilnya

Tabel 2. Bentuk Penerapan dan Kondisi Hunian Berkelanjutan Aspek Lingkungan

\begin{tabular}{|c|c|c|c|c|c|c|}
\hline No & $\begin{array}{l}\text { Sub Variabel } \\
\text { / Indikator }\end{array}$ & Definisi Indikator & Bentuk Penerapan & $\begin{array}{l}\text { Sudah } \\
\text { Berhasil }\end{array}$ & $\begin{array}{l}\text { Belum } \\
\text { Optimal }\end{array}$ & $\begin{array}{c}\text { Belum } \\
\text { Dilakukan }\end{array}$ \\
\hline \multirow[t]{3}{*}{1} & \multirow{3}{*}{$\begin{array}{l}\text { Memastikan } \\
\text { efisiensi } \\
\text { energi, } \\
\text { generasi } \\
\text { mikro, air } \\
\text { dan efisiensi } \\
\text { sumber daya }\end{array}$} & $\begin{array}{l}\text { Meminalkan } \\
\text { kebocoran dan } \\
\text { air tumpah }\end{array}$ & $\begin{array}{l}\text { Kebocoran air bersih } \\
\text { pada unit hunian } \\
\text { diminalkan dengan } \\
\text { mendatangkan tehknisi } \\
\text { untuk memperbaiki } \\
\text { kebocoran. }\end{array}$ & $\checkmark$ & & \\
\hline & & $\begin{array}{l}\text { Sistem } \\
\text { pengumpulan air } \\
\text { hujan }\end{array}$ & $\begin{array}{l}\text { Sudah terdapat sumur } \\
\text { resapan berjumlah } 15 \\
\text { titik setiap blok untuk } \\
\text { mengumpulkan air hujan }\end{array}$ & $\checkmark$ & & \\
\hline & & $\begin{array}{l}\text { Penggunaan } \\
\text { kembali air }\end{array}$ & $\begin{array}{l}\text { Sudah terdapat sistem } \\
\text { penggunaan air kembali } \\
\text { seperti IPAL }\end{array}$ & & $\checkmark$ & \\
\hline
\end{tabular}




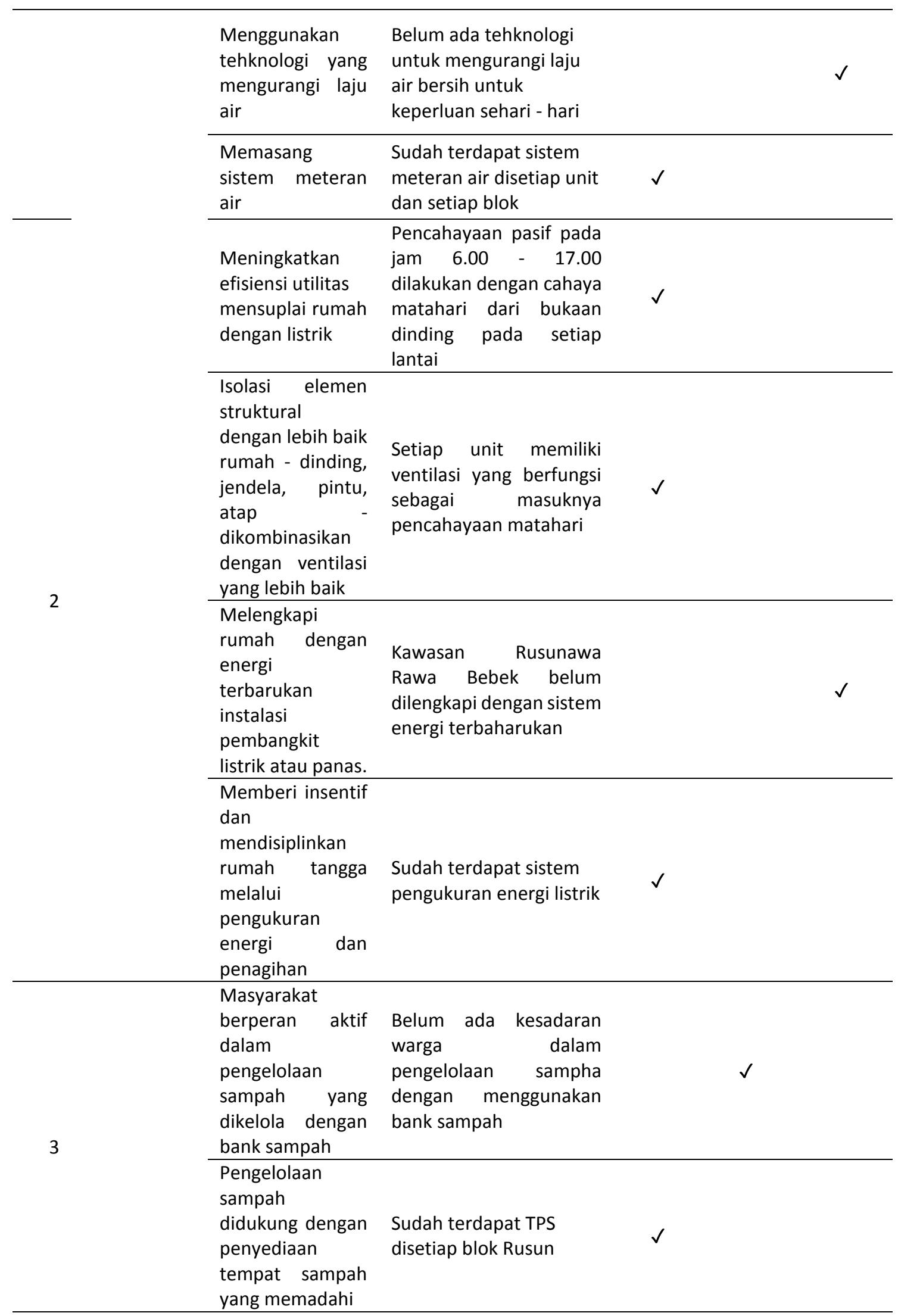




\begin{tabular}{|c|c|c|c|c|c|}
\hline & & $\begin{array}{l}\text { Mempermudah } \\
\text { sistem } \\
\text { pengelolaan } \\
\text { maka dilakukan } \\
\text { pembedaan shaft } \\
\text { sampah organik } \\
\text { dan anorganik } \\
\end{array}$ & $\begin{array}{l}\text { Belum ada sistem } \\
\text { pembedaan shaft } \\
\text { sampah }\end{array}$ & & $\checkmark$ \\
\hline 4 & $\begin{array}{l}\text { Desain hijau, } \\
\text { menggunaka } \\
\mathrm{n} \text { konstruksi } \\
\text { lokal yang } \\
\text { berkelanjuta } \\
\mathrm{n} \text { dan bahan }\end{array}$ & $\begin{array}{l}\text { Ramah } \\
\text { lingkungan, } \\
\text { dengan desain } \\
\text { bangunan yang } \\
\text { memanfaatkan } \\
\text { pencahayaan dan } \\
\text { penghawaaan } \\
\text { alami }\end{array}$ & $\begin{array}{l}\text { Desain bangunan Rusun } \\
\text { memiliki dinding bukaan } \\
\text { pada setiap lantai yang } \\
\text { dapat memanfaatkan } \\
\text { matahari sebagai } \\
\text { pencahayaan alami }\end{array}$ & $\checkmark$ & \\
\hline & & $\begin{array}{l}\text { Memiliki } \\
\text { pembuangan air } \\
\text { kotor dan } \\
\text { drainase yang } \\
\text { terintegrasi } \\
\text { dengan saluran } \\
\text { pembuangan air } \\
\text { kota }\end{array}$ & $\begin{array}{l}\text { Pembuangan air kotor } \\
\text { dari setiap unit sudah } \\
\text { terintegrasi dengan } \\
\text { saluran pembuangan air } \\
\text { kota }\end{array}$ & $\checkmark$ & \\
\hline 5 & $\begin{array}{l}\text { Sanitasi, } \\
\text { mencegah } \\
\text { bahan - } \\
\text { bahan } \\
\text { berbahaya } \\
\text { dan polusi }\end{array}$ & $\begin{array}{l}\text { Pengelolahan } \\
\text { dan Pemanfaatan } \\
\text { Ulang Air dan } \\
\text { daur ulang } \\
\text { limbah: } \\
\text { Pemenuhan } \\
\text { sumber daya air } \\
\text { dapat dilakukan } \\
\text { dengan pengolahan air } \\
\text { pengah rumah } \\
\text { limbah yang } \\
\text { tangga rusun } \\
\text { dihasilkan dengan IPAL } \\
\text { denal }\end{array}$ & $\begin{array}{l}\text { Sudah terdapat sistem } \\
\text { pemanfaatan ulang air } \\
\text { limbah berupa IPAL }\end{array}$ & & $\checkmark$ \\
\hline \multirow{3}{*}{6} & \multirow{3}{*}{$\begin{array}{l}\text { Sistem } \\
\text { keamanan } \\
\text { lingkungan }\end{array}$} & $\begin{array}{l}\text { Pengadaan } \\
\text { petugas } \\
\text { keamanan dari } \\
\text { pemerintah, }\end{array}$ & $\begin{array}{l}\text { Sudah terdapat petugas } \\
\text { keamanan dari } \\
\text { pemerintah dengan } \\
\text { mempekerjakan warga } \\
\text { Rusun maupun disekitar } \\
\text { rusun sebagai petugas } \\
\text { keamanan }\end{array}$ & $\checkmark$ & \\
\hline & & $\begin{array}{l}\text { Pembangunan } \\
\text { infrastruktur lain } \\
\text { seperti pos jaga, } \\
\text { dinding keliling } \\
\text { rumah susun, }\end{array}$ & $\begin{array}{l}\text { Sudah } \\
\text { infrastruktur pos jaga } \\
\text { dan dinding keliling }\end{array}$ & $\checkmark$ & \\
\hline & & $\begin{array}{l}\text { Membangun } \\
\text { kesadaran warga } \\
\text { untuk saling } \\
\text { mengawasi }\end{array}$ & $\begin{array}{l}\text { Membangun kesadaran } \\
\text { dengan sosialiasi } \\
\text { membangun kehidupan } \\
\text { bermasyarakat yang } \\
\text { harmonis }\end{array}$ & $\checkmark$ & \\
\hline
\end{tabular}

Sumber : Olahan Peneliti, 2021 
Tabel 3. Bentuk Penerapan dan Kondisi Hunian Berkelanjutan Aspek Sosial

\begin{tabular}{|c|c|c|c|c|c|c|}
\hline No & $\begin{array}{l}\text { Sub Variabel / } \\
\text { Indikator }\end{array}$ & $\begin{array}{l}\text { Definisi } \\
\text { Indikator }\end{array}$ & $\begin{array}{c}\text { Bentuk } \\
\text { Penerapan }\end{array}$ & $\begin{array}{c}\text { Sudah } \\
\text { Dilakukan }\end{array}$ & $\begin{array}{c}\text { Belum } \\
\text { Optima }\end{array}$ & $\begin{array}{c}\text { Belum } \\
\text { Dilakuka } \\
n\end{array}$ \\
\hline
\end{tabular}

1

Memberdayaka n masyarakat dan memastikan partisipasi publik.

2

Memastikan kesehatan,

keselamatan, kesejahteraan pada rumah tinggal
Terdapat

pelatihan berupa

Memberdayaka

n masyarakat

(enpowerment)

membatik yang

diadakan setiap

senin sampai

jumat. Tetapi

peserta membatik

hanya 15 orang.

\begin{tabular}{|c|c|}
\hline $\begin{array}{l}\text { Memastikan } \\
\text { partisipasi } \\
\text { publik }\end{array}$ & $\begin{array}{l}\text { Partisipasi publik } \\
\text { langsung } \\
\text { dilakukan dengan } \\
\text { warga rusun aktif } \\
\text { dalam memberika } \\
\text { ide dan pendapat } \\
\text { saar rapat dengan } \\
\text { masing - masing } \\
\text { RT. Beberapa RT } \\
\text { juga mengadakan } \\
\text { program iuran } \\
\text { dan warga cukup } \\
\text { aktif dalam } \\
\text { membayar iuran } \\
\text { yang digunakan } \\
\text { untuk keperluan } \\
\text { bersama tersebut. }\end{array}$ \\
\hline $\begin{array}{l}\text { Keselamatan } \\
\text { dari bencana } \\
\text { kebakaran }\end{array}$ & $\begin{array}{l}\text { Infrastruktur } \\
\text { keselamatan } \\
\text { kebakaran di } \\
\text { Rusunawa Rawa } \\
\text { Bebek yaitu alarm } \\
\text { kebakaran, APAR, } \\
\text { Hydrant, dan } \\
\text { Koneksi Hydrant. } \\
\text { Sampai saat ini } \\
\text { kebakaran pernah } \\
\text { terjadi di } \\
\text { beberapa unit. } \\
\text { Tetapi } \\
\text { penangananya } \\
\text { cepat sehingga } \\
\text { kebakaranya tidak } \\
\text { meluas bahkan } \\
\text { membakar unit } \\
\text { tersebut. }\end{array}$ \\
\hline
\end{tabular}




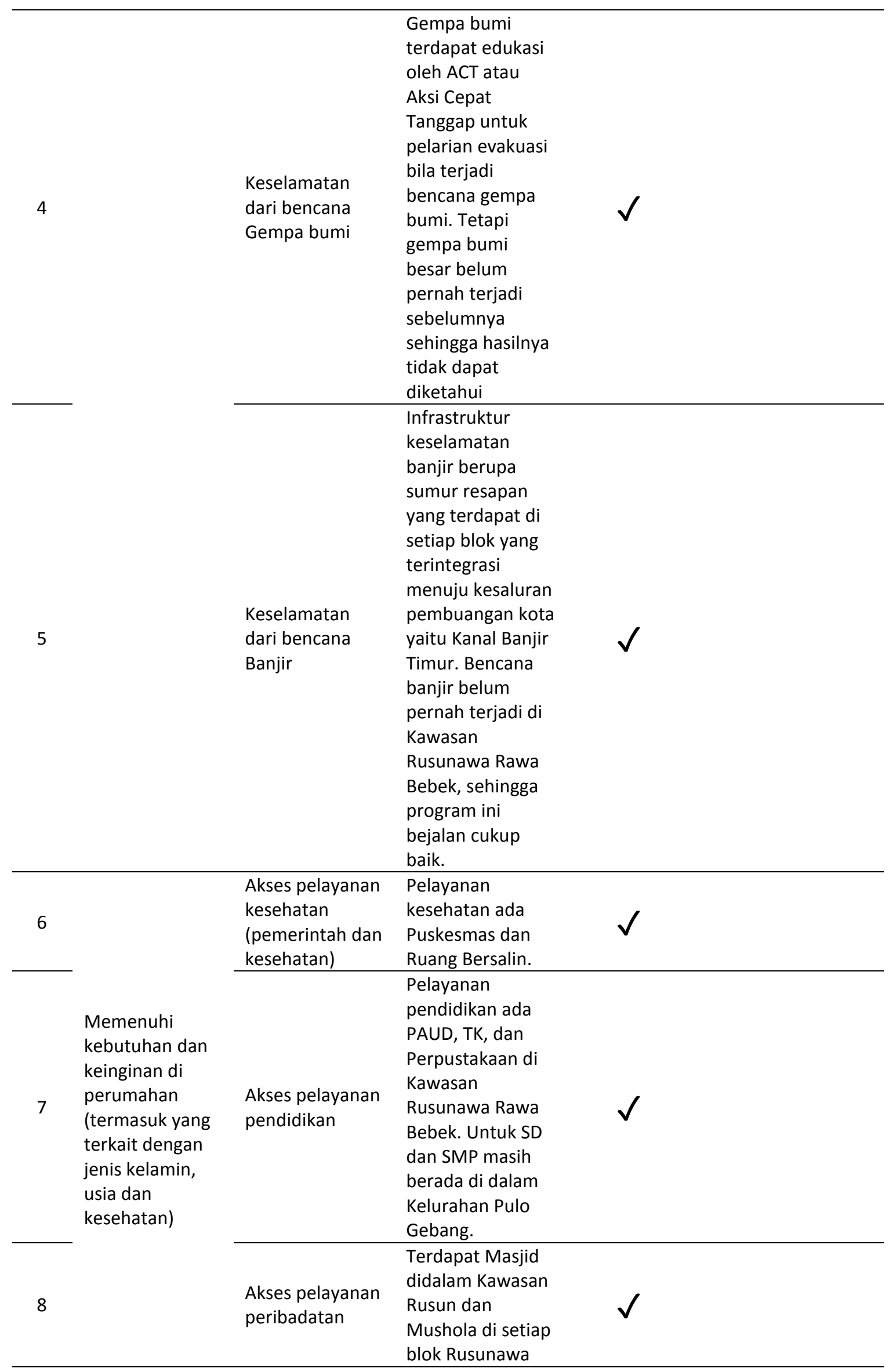




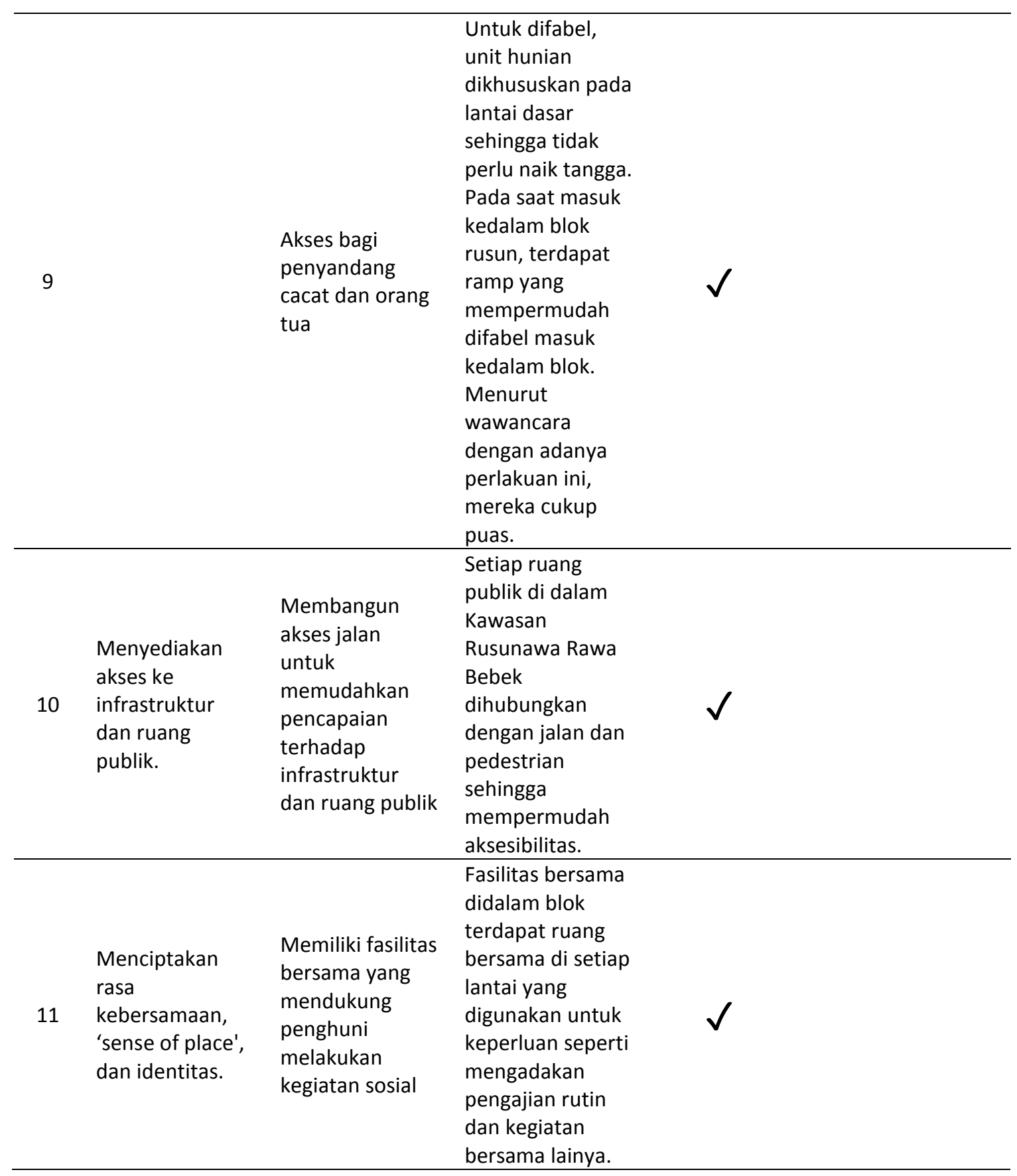


Tabel 4. Bentuk Penerapan dan Kondisi Hunian Berkelanjutan Aspek Ekonomi

\begin{tabular}{|c|c|c|c|c|c|c|}
\hline No & $\begin{array}{c}\text { Sub Variabel / } \\
\text { Indikator }\end{array}$ & $\begin{array}{c}\text { Definisi } \\
\text { Indikator }\end{array}$ & Bentuk Penerapan & $\begin{array}{c}\text { Sudah } \\
\text { Dilakukan }\end{array}$ & $\begin{array}{l}\text { Belum } \\
\text { Optimal }\end{array}$ & $\begin{array}{c}\text { Belum } \\
\text { Dilakukan }\end{array}$ \\
\hline 1 & $\begin{array}{l}\text { Memastikan } \\
\text { keterjangkauan } \\
\text { perumahan bagi } \\
\text { kelompok- } \\
\text { kelompok sosial } \\
\text { yang berbeda. }\end{array}$ & $\begin{array}{l}\text { Uang Sewa } \\
\text { yang } \\
\text { terjangkau }\end{array}$ & $\begin{array}{l}\text { Harga uang sewa untuk } \\
\text { warga terprogram } \\
\text { (relokasi) oleh pemerintah } \\
\text { dilakukan subsidi sehingga } \\
\text { dapat membayar lebih } \\
\text { murah. Menurut beberapa } \\
\text { ketua RT, warga yang } \\
\text { menunggak pembayaran } \\
\text { uang sewa dikarenakan } \\
\text { sengaja tidak membayar. } \\
\text { Alasanya dikarenakan } \\
\text { masih "sakit hati" akibat } \\
\text { penggusuran tempat } \\
\text { tinggal dahulunya yang } \\
\text { tidak diberikan kompensasi } \\
\text { (uang). }\end{array}$ & & $\sqrt{ }$ & \\
\hline 2 & $\begin{array}{l}\text { Menyediakan } \\
\text { tempat tinggal } \\
\text { yang memadai } \\
\text { untuk } \\
\text { meningkatkan } \\
\text { produktivitas } \\
\text { tenaga kerja; } \\
\text { Memastikan } \\
\text { perumahan } \\
\text { terintegrasi } \\
\text { dengan } \\
\text { pekerjaan }\end{array}$ & $\begin{array}{l}\text { Memastikan } \\
\text { perumahan } \\
\text { terintegrasi } \\
\text { dengan } \\
\text { pekerjaan }\end{array}$ & $\begin{array}{l}\text { Para warga yang bekerja } \\
\text { pada tempat tinggal } \\
\text { sebelum relokasi diberika } \\
\text { akses gratis menggunakan } \\
\text { Transjakarta yang } \\
\text { terintegrasi dengan tempat } \\
\text { pekerjaanya. }\end{array}$ & & & \\
\hline 3 & $\begin{array}{l}\text { Mendukung } \\
\text { kegiatan } \\
\text { ekonomi } \\
\text { berbasis rumah } \\
\text { tangga } \\
\text { (UBR)/Home } \\
\text { Based Enterprise }\end{array}$ & $\begin{array}{l}\text { Mendukung } \\
\text { kegiatan } \\
\text { ekonomi } \\
\text { berbasis } \\
\text { rumah } \\
\text { tangga } \\
\text { (UBR)/Home } \\
\text { Based } \\
\text { Enterprise }\end{array}$ & $\begin{array}{l}\text { lima prinsip UBR berjalan } \\
\text { cukup baik dan lima tipe } \\
\text { UBR seperti manufaktur, } \\
\text { jasa, penjualan (distribusi), } \\
\text { pertanian, dan lain - lain } \\
\text { sudah terdapat didalam } \\
\text { Kawasan Rusunawa Rawa } \\
\text { Bebek }\end{array}$ & 1 & & \\
\hline
\end{tabular}

Sumber : Olahan Peneliti, 2021

\section{KESIMPULAN DAN SARAN}

\section{Kesimpulan}

Berdasarkan pembahasan dan tujuan penelitian diatas, dapat disimpulkan bentuk penerapan serta kondisi aspek hunian berkelanjutan di Rusunawa Rawa Bebek sebagai berikut Pada aspek lingkungan Rusunawa Rawa Bebek telah menerapkan upaya untuk memastikaan efisiensi air seperti dalam meminimalkan kebocoran dan air tumpah, memiliki sistem pengumpulan air hujan, dan memasang sistem meteran air yang digunakan untuk mengukur pengeluaran air bersih. Untuk penerapan efisiensi energi, Rusunawa Rawa Bebek telah meningkatkan efisiensi utilitas, mengkombinasikan dinding, jendela, pintu dengan ventilasi yang lebih baik, serta memberikan insentif dan mendisiplinkan rumah tangga dengan pengukuran energi dan penagihan. Untuk persampahan sendiri pengelolaan sampah sudah 
didukung dengan penyediaan tempat sampah yang memadai di seetiap blok rusun. Desain hijau berupa ramah lingkungan dengan desai bangunan yang memanfaatkan pencahayaan dan penghawaan alami juga telah dilakukan. Untuk sanitasi, pembuangan air limbah dan drainase sudah terintegrasi dengan saluran pembuangan kota yaitu Kanal Banjir Timur. Serta sistem keamanan lingkungan deengan pengadaan petugas keamanan, infrastruktur keamanan seperti pos jaga dan dinding keliling rumah susun, dan kesadaran warga untuk mengawasi antar warganya.

Aspek sosial yang telah diterapkan adalah pemberdayaan masyarkat dan juga pemastian partisipasi masayarakatnya, memastikan kesehatan, dan keselatan rumah tinggal dengan terdapatnya infrastruktur keamanan dari bencana kebakaran, banjir,dan gempa bumi, lalu pemenuhan kebutuhan dan keinginan di permahan dalam pelayanan kesehatan, pendidikan, peribadatan, dan difabel, menyediakan akses menuju ruang publik, dan menciptakan rasa kebersamaan dan rasa saling memiliki.s

Aspek ekonomi yang diterapkan adalah keterjangkauan bagi kelompok sosial yang berbeda dengan cara memastikan keterjangkauan uang sewa, menyediakan tempat tinggal untuk meningkatkan produktivitas dengan memastikan tempat pekerjaan dan perumah saling terintegrasi, dan kegiatan ekonomi berbasis rumah tangga yang telah berjalan di dalam Kawasan Rusunawa Rawa Bebek.

\section{Saran}

Saran yang peneliti berikan terkait dengan aspek - aspek hunian berkelanjutan yang perlu ditingkatkan dikarenakan hasil evaluasi yang belum optimal dan belum dilakukan. Saran yang diberikan berdasarkan rusunawa yang memiliki karakteristik yang sama dan dari kajian teori maupun standar yang berhubungan dengan hunian berkelanjutan. Saran tersebut sebagai berikut :

Pengoptimalan fungsi IPAL sebagai utilitas untuk penggunaan air kembali dengan cara ;Pemisahan pembuangan limbah domestic dari hunian (grey water dan black water) agar fungsi IPAL dapat optimal dan pengadaan zat kimia atau bakteri pengurai untuk pembersihan air, menggunakan tehknologi "showerhead" sebagai alternatif alat untuk mandi pada unit hunian agar dapat mengurangi laju air (Council, U.S. Green Building, 2020), mengadakan instalasi energi terbaharukan untuk pembangkit listrik atau panas berupa solar panel atau panel surya, mengkaji ulang mengenai harga untuk menjual sampah di program bank sampah untuk menumbuhkan semangat nasabah bank sampah, mendesain bangunan Rusunawa dengan pembedaan shaft sampah organic dan anorganik, berkomunikasi kepada warga yang masih "marah" karena dampak penggusuran yang tidak mendapatkan kompensasi, agar mencari solusi terbaik sehingga warga tersebut tidak menunggak pembayaran uang sewa.

\section{REFERENSI}

Council, U.S. Green Building. (2020). LEED v4.1 Residential Multifamily. Retrieved from LEED v4.1: https://www.usgbc.org/leed/v41\#residential

Golubchikov, O., \& Badyina, A. (2012). Sustainable Housing for Sustainable Cities : a Policy Framework for Developing Countries. Nairobi: UN-Habitat.

Rosilawati, H. (2016). Konsep Hunian Berkelanjutan Pada Rumah Susun (Studi Kasus Rusunawa Dupak Bangunrejo, Surabaya). Surabaya.

Tanuwidjaja, G., Mustakim, Wangsadirja, M. H., \& Sudarman, A. (2010). Integrasi Kebijakan Perencanaan dan Desain Rumah Susun yang Berkelanjutan, Dalam Konteks Pembangunan Kota yang Berkelanjutan.

Undang - Undang Tentang Perlindungan dan Pengelolaan Lingkungan Hidup. (2009). UU 32 Tahun 2009. Jakarta, Indonesia: Menteri Hukum dan Hak Asasi Manusia.

Widyasari, A. (2017). Konsep Rumah Susun Berkelanjutan di Kawasan Industri (Studi Kasus : Rungkut, Surabaya). Surabaya. 